\title{
Construindo um jogo para o ensino de biorremediação
}

\author{
Anderson Rocha ${ }^{1}$, Anna Mendes ${ }^{2}$, Myrna Amorim", \\ Guilherme Matos ${ }^{1}$, Joel dos Santos ${ }^{1}$ \\ ${ }^{1}$ Grupo de Pesquisa em Multimídia - CEFET/RJ \\ ${ }^{2}$ Fundação Osório \\ anderson.rochadaluno.cefet-rj.br, mendes.anna.clgmail.com \\ \{myrna.amorim, guilherme.matos, joel.santos\}@cefet-rj.br
}

\begin{abstract}
Bioremediation consists of using living organisms, plants or microorganisms, to remove or remedy pollutants in the environment. Such theme can be considered of greate potential for teaching concepts and competencies related to Natural Sciences, in Basic Education. Among the approaches used in teaching to instigate students, one may highlight the Problem-Based Learning. In this study, that methodology was associated to educational games, which are also pointed as didactic tools to make learning playful. This work discusses the creation and use of a simmulator/game that uses real environmental problem-situations, as well as the tools for the student solve them. Therefore, the goal is to enable students to learn important concepts related to Bioremediation and related areas, besides developing competencies related to solving problem-situations employing the applied scientific method. For this, a game validation inside a didactic sequence was conducted with five students with a prototype of the game to analyze the results and conclude whether it is feasible to use it as a learning tool. The results were satisfactory, indicating that the participants were able to acquire important skills related to bioremediation and were able to mobilize the necessary knowledge for practical application.
\end{abstract}

Resumo. A biorremediação consiste na utilização de organismos vivos, plantas ou micro-organismos, com vistas a reduzir ou eliminar poluentes presentes no ambiente. Tal temática, assim, pode ser considerada de grande potencial para ensino de conteúdos e competências presentes dentro das Ciências da Natureza, na Educação Básica. Dentre as abordagens utilizadas em ensino com o objetivo de instigar os alunos, destaca-se a aprendizagem baseada em problemas. No presente estudo, essa metodologia foi associada aos jogos educacionais que também são apontados como ferramentas didáticas que trazem o lúdico para sala de aula. O presente trabalho discute a criação e o emprego de um simulador/jogo que emprega situações-problemas ambientais reais, assim como as ferramentas para que o estudante consiga solucioná-las. Sendo assim, o objetivo é oportunizar aos educandos o aprendizado de conceitos importantes sobre biorremediação e áreas correlatas; assim como o desenvolvimento de competências relacionadas a resoluções de situações-problemas pautados no emprego do método científico aplicado. Para isso foi conduzida uma etapa de validação do jogo em uma sequência didática com um grupo de 5 alunos com um protótipo do jogo com vistas a analisar os resultados preliminares relativos a viabilidade 
de sua utilização como ferramenta de ensino. Os resultados se mostraram satisfatórios, indicando que os participantes conseguiram adquirir competências importantes relativas a biorremediação e conseguiram mobilizar os conhecimentos necessários para sua aplicação prática.

\section{Introdução}

A biotecnologia é uma área que vem evoluindo nos últimos anos. Segundo o artigo 2 da Convenção sobre Diversidade Biológica ${ }^{1}$, a biotecnologia pode ser definida como: "Qualquer tecnologia que utilize sistemas biológicos, organismos vivos, ou seus derivados, para fabricar ou modificar produtos ou processos para utilização específica”. Uma das ferramentas utilizadas dentro da biotecnologia é a biorremediação, que usa organismos vivos, plantas ou micro-organismos para remover ou remediar poluentes no ambiente [Mallmann et al. 2019]. Este processo é o melhor, do ponto de vista ecológico, para remover contaminantes com moléculas difíceis de degradar, pois possui baixo impacto no meio ambiente e nas populações que vivem nas proximidades [Mallmann et al. 2019].

Apesar da evolução no uso da biorremediação, a abordagem deste assunto em salas de aula não é uma tarefa fácil. A complexidade do assunto faz com que este tema seja um importante candidato a ser explorado, visto que oportuniza o desenvolvimento de competências importante no estudo das Ciências por meio de uma abordagem multidisciplinar e com possibilidade de aplicação prática de conhecimento para a resolução de situação-problema.

Nesse contexto, a Aprendizagem Baseada em Problemas (ABP) surge como um alternativa didática para aprendizado de alunos. A abordagem da ABP propõe a exposição do aluno a situações reais para as quais este deve buscar uma solução, permitindo assim a construção do conhecimento. A ABP é um método que tem como objetivo transformar o aluno no protagonista do próprio aprendizado por meio da investigação, tornando os professores facilitadores do processo de aquisição de conhecimento [Souza and Dourado 2015]. Neste método, os problemas são um estimulador para a aprendizagem e para o aprimoramento das habilidades de resolução dos alunos.

A ABP enfatiza muito mais a compreensão do que a memorização [Souza and Dourado 2015]. Outro ponto importante da ABP é que ela utiliza o trabalho em equipe para a solução de problemas, de forma que os alunos possam discutir suas ideias com seus colegas, desenvolver habilidades interpessoais e trabalho em equipe, características importantes no desenvolvimento pessoal e profissional.

Outra abordagem com crescente uso são os jogos educacionais. Conforme [Prieto et al. 2005, Araújo et al. 2017], para um jogo ser caracterizado como educacional ele "deve possuir objetivos pedagógicos e sua utilização deve estar inserida em um contexto e em uma situação de ensino baseados em uma metodologia que oriente o processo, por meio da interação, da motivação e da descoberta, facilitando a aprendizagem de um conteúdo". Segundo [Paiva and Tori 2017], a utilização desses tipos de jogos pode trazer diversos benefícios no processo de aprendizado como: (i) efeito motivador, pois os jogos educacionais demonstram ter alta capacidade de gerar diversão e entretenimento

\footnotetext{
${ }^{1}$ https://antigo.mma.gov.br/component/k2/item/7513-convencao-sobrediversidade-biologica-cdb. html. Acessado em 10 de dezembro de 2020.
} 
e, simultaneamente, incentivar o aprendizado; (ii) facilitador de aprendizado, visto que os jogos digitais educacionais tem capacidade de facilitar o aprendizado em vários campos do conhecimento por viabilizar a representação gráfica de uma grande variedade de conteúdos; (iii) desenvolvimento de habilidades cognitivas, pelos jogos promovem o desenvolvimento intelectual por meio de desafios fazendo com que o jogador elabore estratégias e entenda como diferentes elementos do jogo se relacionam para progredir; (iv) aprendizado por descoberta, onde os jogadores desenvolvem a capacidade de explorar, experimentar e colaborar por estarem num ambiente livre de riscos que provoca a experimentação e exploração, estimulando a curiosidade;e, (v) socialização, na medida que os jogos aproximam os alunos jogadores por meio da competição ou cooperação.

Há diversos jogos de biologia que foram desenvolvidos. Em [Marques 2019] os jogadores utilizam técnicas de controle biológico para o controle de pragas em uma plantação, em [Spiegel et al. 2008] estes devem encontrar soluções para problemas relacionados à biologia celular e em [Carvalhal et al. 2002] os jogadores fazem associações entre a ação de microrganismos e situações do cotidiano. Tais jogos buscam promover o ensino por meio da resolução de situações-problema, ou seja, fazem com que o aluno busque entender mais sobre o tema por meio dessa construção.

Este artigo, portanto, apresenta a proposta de um jogo educacional com o objetivo de auxiliar o aluno no aprendizado de biorremediação e no desenvolvimento de competências relacionadas a educação científica. Este jogo trabalha o assunto por meio da apresentação de situações-problema aos alunos. Estando no papel de um biólogo, os alunos devem escolher para cada situação proposta uma dentre as técnicas de biorremediação disponíveis de forma a obter um melhor custo-benefício entre o gasto e tempo de descontaminação. Por meio do jogo espera-se que o aluno esteja apto a compreender o tema por outra perspectiva.

Visando avaliar a aceitação do jogo e como ele mobiliza os conceitos de biorremediação, uma etapa de validação do jogo e da sequência didática foi realizada com cinco alunos do ensino médio da rede pública. Vale ressaltar que, inicialmente, foi desenvolvido apenas um protótipo do jogo a ser validado pelas opiniões dos participantes e os resultados da sequência didática.

O artigo está estruturado como segue. A Seção 2 apresenta como os conceitos de biorremediação são abordados no jogo. A Seção 3 apresenta a sequência didática conduzida e os resultados obtidos. Por fim, a Seção 5 conclui este artigo e apresenta os trabalhos futuros.

\section{Game Design}

Por simplicidade, no restante deste artigo o protótipo do jogo será denominado JB (Jogo de Biorremediação). O JB foi desenvolvido tendo como público-alvo estudantes do ensino médio e superior que estejam estudando alguma área da biologia, para que assim consigam potencializar as informações obtidas acerca do tema biorremediação. No JB, o jogador é colocado no papel de um biólogo que viaja o mundo descontaminando áreas ambientais utilizando técnicas de biorremediação. Desta forma, cada fase do jogo se passa em um ambiente diferente, o que permite ao jogador se deparar com diferentes situações-problemas. A Figura 1 exibe o mapa de fases do jogo.

Cada situação problema apresentada por meio da fase é composta pelos fatores: 


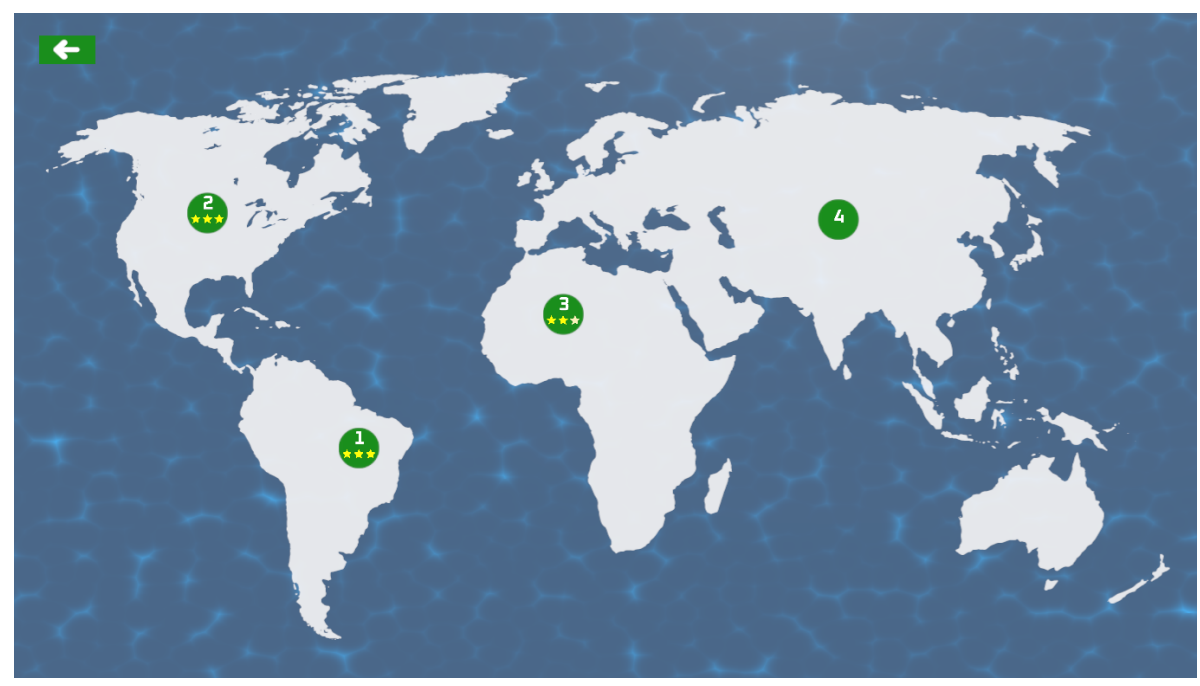

Figura 1. Tela de escolha de fases do JB.

(i) população microbiana, (ii) tipo do contaminante, (iii) umidade, (iv) $\mathrm{pH}$ e (v) temperatura.A combinação desses fatores varia de acordo com a fase. Por fim, cada fase apresenta uma taxa de contaminação alvo que o jogador terá que alcançar por meio do uso das técnicas de biorremediação. Logo, o jogador terá que analisar as variáveis acima para fazer o uso da melhor técnica recomendada em um dado momento. O objetivo na fase é o jogador conseguir resolver a situação problema, que é mensurada pelo nível de contaminação obtido.

As fases possuem apenas três técnicas disponíveis: atenuação natural, bioestimulação e bioaumento. A técnica de Atenuação natural não gera nenhuma mudança no jogo, pois consiste apenas em monitorar o ecossistema. A Bioestimulação consiste em inserir nutrientes no solo de forma que a população microbiana tenha mais nutrientes. Por fim, o Bioaumento aumenta a carga de uma bactéria específica na população microbiana.

Caso o jogador escolha a técnica de Bioestímulo, o resultado obtido é um aumento da efetividade das bactérias presentes no ambiente. Caso uma bactérica degradadora do contaminante esteja presente no perfil de bactérias, este será degradado com maior velocidade. No caso do Bioaumento, a população de uma determinada bactéria, escolhida pelo jogador, é aumentada. Caso o bioaumento seja feito em uma bactéria que degrada o contaminante, como consequência, o nível de contaminação do ambiente reduzirá mais rapidamente.

A Figura 2 exibe a tela de uma fase do jogo. $\mathrm{Na}$ área inferior esquerda da tela é exibido um gráfico de abundancia relativa que é um conceito estatístico usado na biologia para mostrar a quantidade de espécies em um determinado habitat [Volkov et al. 2003]. No jogo o gráfico é utilizado para exibir uma população microbiana do ecossistema. Cada cor retrata uma população de bactéria, que pode ser degradadora do contaminante ou não. O jogador pode visualizar informações da bactéria na legenda do gráfico, onde é exibido o nome e quantidade absoluta de cada bactéria. A parte central inferior mostra o gráfico de contaminação do solo. No eixo x são exibidos os dias e no eixo y a porcentagem de contaminação. Este gráfico serve de feedback para o jogador. Assim, permite-se que o jogador avalie suas hipóteses conforme o desenrolar do jogo, num processo de aprendizado 


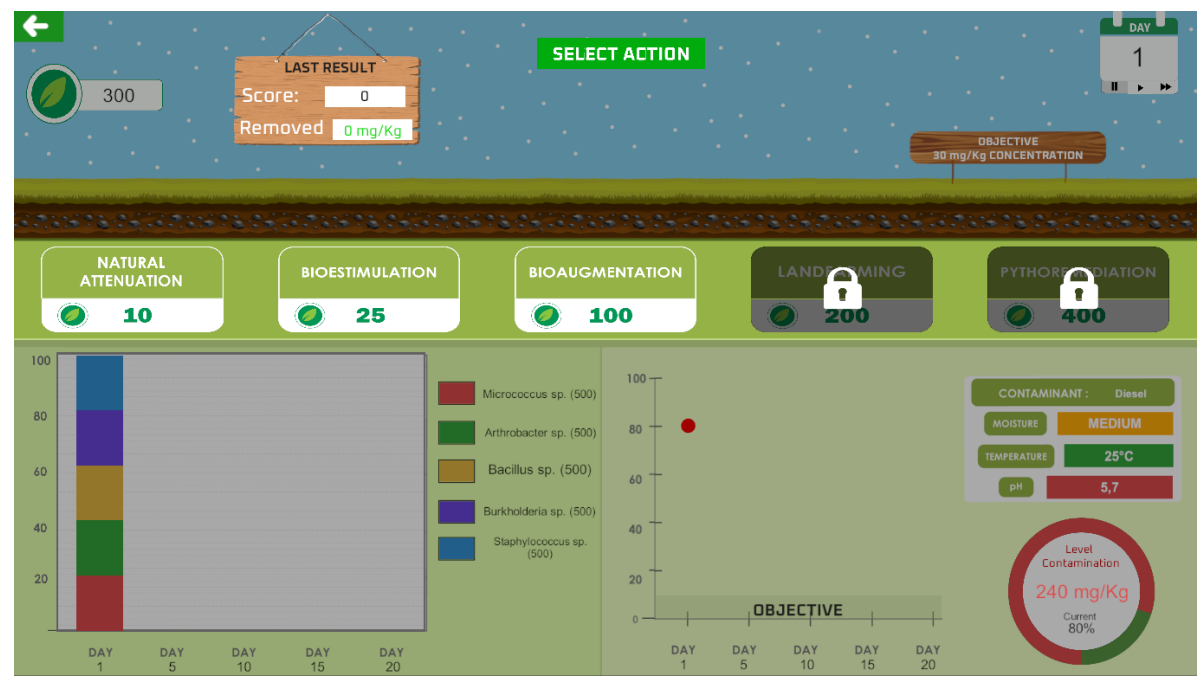

Figura 2. Protótipo de uma fase do jogo.

por descoberta conforme discutido por [Paiva and Tori 2017].

Na parte inferior direita são apresentadas informações do ecossistema que podem influenciar na decisão do jogador. Conforme discutido em [Jacques et al. 2007], a umidade é um fator importante para o solo, pois uma alta atividade microbiana só ocorrerá se houver adequada disponibilidade de água aos microrganismos. A temperatura afeta a atividade metabólica, o consumo de substrato pelos microrganismos e consequentemente a biodegradação do contaminante. $\mathrm{O}$ pH do solo afeta diretamente a atividade dos microrganismos por alterar a permeabilidade celular, a atividade enzimática e a disponibilidade de micro e macronutrientes do solo. O jogo aborda o impacto desses fatores na biorremediação por meio da definição de intervalos de umidade, temperatura e $\mathrm{pH}$ ideais para cada técnica. A umidade assume três valores: low, medium e high. Quanto mais alta é a umidade melhor a taxa de degradação das bactérias, ou seja, ela descontaminará o poluente mais rapidamente. Já em temperatura e $\mathrm{pH}$ ambos trabalham juntos bonificando ou prejudicando o efeito da técnica usada. Esses dois fatores possuem três intervalos baseados em [Atagana et al. 2003] e [Andrade et al. 2010]. Se os fatores estiverem dentro da faixa ideal, os efeitos da técnica são potencializados, do contrário, quando os valores estão fora dessa faixa ideal, o efeito da técnica é reduzido.

Um dos objetivos do JB é que o aluno consiga identificar a relação de custo benefício de cada técnica em termos do gasto e tempo para descontaminação. Dessa forma, o jogo marca a passagem do tempo com um sistema de dias. As características do ambiente (umidade, temperatura e $\mathrm{pH}$ ) variam a cada 100 dias. Já os gráficos de população microbiana e descontaminação são atualizados a cada 5 dias. A cada 30 dias o jogador é obrigado a tomar uma decisão escolhendo uma das técnicas disponíveis.

O jogo utiliza um sistema de pontuação baseado em uma moeda do JB. O jogador gasta moedas na escolha de uma das técnicas e ganha moedas conforme a descontaminação obtida. Vence a fase o jogador que atingir o percentual alvo de poluição, que varia de acordo com fase. Além disso, visando forçar a percepção do custo benefício de cada técnica, o JB faz com que o jogador perca moedas conforme o tempo passa, simulando uma multa ambiental ou depreciação do terreno. O jogador que gastar todas as moedas perde 
a fase, pois não será possível utilizar as técnicas. Neste caso, será necessário reiniciar a fase.

\section{Sequência didática}

Com o objetivo de avaliar o uso do JB como ferramenta de aprendizado, foi realizada uma sequência didática com alunos do ensino médio da rede pública. A sequência didática usou como base teórica o Ensino por investigação, sendo apresentada uma questão problema para que o participante buscasse sua solução. A utilização do Ensino por investigação proporciona ao docente a oportunidade não somente de verificar a aprendizagem por parte dos alunos, mas também de observar se eles sabem argumentar, falar, debater, ler e escrever sobre o conteúdo aprendido [Carvalho 2018]. A avaliação contou com um conjunto inicial de 6 alunos, posteriormente sendo reduzido para 5 devido a desistência do sexto participante. A sequência foi feita em dupla para estimular a cooperação dos participantes, devido a desistência, o participante 5 realizou as etapas individualmente.

\subsection{Procedimento}

A sequência didática foi dividida em três etapas. A duração total da sequência didática foi de 96 horas, sendo 24 horas disponibilizadas para a primeira e terceira etapas. A segunda etapa foi realizada em 48 horas.

Na primeira etapa os participantes preencheram um questionário para identificar as percepções de conhecimento sobre biorremediação e dentre as perguntas, foram incluídas questões para caracterização do perfil socioeconômico como mostra a Tabela 1.

\section{Perguntas}

1. Idade

2. Qual a sua escolaridade?

3. Onde você realizou seus estudos de Ensino Fundamental ou equivalente?

4. Onde você está cursando o ensino médio?

5. Selecione os elementos que você possui em casa: computador, celular, internet banda larga.

6. Você possui acesso a internet?

7. Quantas horas por dia, em média, você gasta com acesso à internet?

8. Que materiais e/ou recursos os professores de Ciências e/ou Biologia costumam utilizar para abordar os tópicos da matéria nas aulas?

9. Você já ouviu falar em biorremediação?

10. Em qual(is) situação(ões) abaixo você já ouviu falar de biorremediação?

Tabela 1. Perguntas do questionário da primeira etapa

A segunda etapa se inicia com a apresentação de uma situação problema aos participantes. A situação problema foi construída de forma a trazer o problema da biorremediação mais próximo da realidade do participante. Nessa etapa, os participantes têm a disposição vídeos de tutorial sobre a interface do JB, sem entrar em detalhes do tema 
biorremediação. Passada a situação problema, os participantes dispõem de 48 horas para jogar e documentar na forma de uma apresentação todo a caminho traçado até a obtenção de uma resposta para a situação problema.

Por fim, a terceira etapa consiste de uma apresentação realizada pelas duplas de participantes por meio do google meet explicando o caminho percorrido para resolver o problema proposto. Durante a apresentação, os participantes ainda foram perguntados sobre a escolha das técnicas empregadas, forma que percorreram até chegar a solução, situações reais que eles podem aplicar o que absorveram por meio do JB e sobre questões específicas a respeito as funcionalidades do JB que não tivessem sido claras em suas apresentações. Após essa apresentação os participantes responderam um segundo questionário cujas perguntas são exibidas na Tabela 2, com perguntas abertas, com o objetivo de validar o uso do jogo como ferramentas de aprendizado.

\section{Perguntas}

1. O jogo possibilitou a vivência de uma estratégia de ensino diferenciada sobre a temática biorremediação. Diante da sua vivência no jogo, como você avaliaria essa estratégia didática?

2. Você acha que a ferramenta ajudou a entender o que é biorremediação?

3. Você conseguiria empregar a biorremediação em quais outros problemas?

4. Você se sentiu estimulado a resolver o problema proposto com o jogo e obter bons resultados?

5. O que você achou da interface do jogo?

6. Qual(is) dificuldade(s) você teve no jogo?

7. O que você mais gostou do jogo?

8. Quais seriam suas sugestões para melhorar o jogo?

9. Você tem algum outro comentário?

Tabela 2. Perguntas do questionário da terceira etapa

\section{Resultados}

Conforme a caracterização feita na primeira etapa, os cinco participantes possuem faixa etária entre 15-18 anos. Todos os participantes estavam cursando o ensino médio em uma escola da rede pública. Os participantes relataram o uso de diferentes materiais em sala pelos professores como slides projetados em sala e vídeos em plataformas online (YouTube, Vimeo, Sparkle etc.), entretanto nenhum relatou o uso de jogos. 60\% responderam conhecer biorremediação por algum de meio de comunicação (TV, internet e jornal), sendo um por meio de aulas de ciências/biologia. Os resultados da primeira etapa mostram que nenhum dos participantes utiliza jogos para o aprendizado de tópicos relacionados a biologia na sala de aula. É importante destacar que a maioria conheceu sobre biorremediação por meio dos meios de comunicação.

Segunda Etapa. Durante a realização da segunda etapa pelos participantes, foi feita uma análise do caminho por eles percorrido de acordo com $\log s$ das ações do jogador. Essa análise tem a finalidade permitir uma comparação com o relato dos participantes na 
terceira etapa. Cabe destacar, entretanto, que não foi possível obter dados de todos os participantes por problemas com a instalação do JB com o participante 1. A Tabela 3 resume a quantidade de tentativas e exibe os status de cada tentativa dos participantes.

\begin{tabular}{|c|ccc|ccc|c|}
\hline & \multicolumn{3}{|c|}{ Fase 1 } & \multicolumn{3}{c|}{ Fase 2 } & \\
Participante & win & lose & quit & win & lose & quit & Tempo (min) \\
\hline 1 & - & - & - & - & - & - & - \\
2 & 3 & 0 & 1 & 1 & 0 & 0 & 17,2 \\
3 & 9 & 1 & 3 & 2 & 0 & 1 & 34,2 \\
4 & 8 & 2 & 10 & 8 & 0 & 3 & 52,5 \\
5 & 1 & 0 & 1 & 0 & 0 & 0 & 6,5 \\
\hline
\end{tabular}

Tabela 3. Dados de vitória, derrota e desistência dos participantes

Na tabela, a coluna win indica a quantidade de vitórias numa dada fase, lose a quantidade de derrotas e quit a quantidade de desistências. Cabe destacar que a quantidade de desistências pode ser associada à derrota numa fase, devido ao fato de o jogador tender a abandonar a fase quando sabe que vai perder. Pela tabela é possível observar que o participante 4 teve dificuldades da fase 1 devido a grande quantidade de abandonos. Contudo, na fase 2 teve um bom aproveitamento obtendo oito vitórias. Por fim, a Tabela 3 exibe o tempo médio jogado. Esse tempo foi calculado com base nos dias (do $\mathrm{JB}$ ) totais multiplicado pelo tempo médio de um dia no JB ( $1 s$ no modo normal e $0,5 s$ no modo rápido, sendo usado o tempo médio de $0,75 \mathrm{~s}$ ). Cabe ressaltar que o tempo de instalação e visualização de tutoriais não foram contabilizados na tabela. Pela análise do tempo, é possível verificar que o tempo cresce conforme maior é o número de tentativas do participante.

Terceira etapa. Na apresentação dos participantes sobre a experiência que tiveram jogando o JB foram destacados os pontos positivos, negativos e dificuldades encontradas durante a sequência didática. Os participantes, em geral, relataram que no início tiveram dificuldades no entendimento do JB e em ganhar as fases nas primeiras tentativas. O participante 2 relatou que fez o processo testando diferentes técnicas com o objetivo de aprender como elas funcionavam. Isso pode ter ocasionado um impacto na pontuação na fase 1, conforme exibido na Tabela 3.

A análise de respostas do segundo questionário, aplicado durante essa etapa, se deu por metodologia qualitativa, segundo a tematização de [Fontoura 2011]. Os temas escolhidos foram: (i) Papel do JB e (ii) Game Design.

A criação do primeiro tema partiu das quatro primeiras perguntas do questionário que, de modo geral, são perguntas relacionadas sobre a experiência do JB. Este tema foi dividido em três categorias: (i) Avaliação enquanto estratégia de ensino, (ii) Conhecimento obtido e (iii) Aplicações do JB. As unidades de contexto em relação a categoria Avaliação enquanto estratégia de ensino estão de acordo com [Paiva and Tori 2017] ao apontarem que o JB possibilita ao aluno entender sobre o tema sem algum contato prévio. Conforme [Paiva and Tori 2017], isso ocorre pelo fato do JB educacional atuar como um facilitador de aprendizado em vários campos do conhecimento. A categoria Conhecimento obtido corrobora com [Souza and Dourado 2015] ao apontar que os participantes conseguiram entender melhor o tema e conseguiram explicar bem o assunto. 
[Souza and Dourado 2015] afirmam que por meio da metodologia da ABP o aluno se torna protagonista de sua aprendizagem, por se sentir motivado, valoriza os conhecimentos obtidos, amplia e desenvolve potencial para novas aprendizagens. Em relação a categoria Aplicações, os participantes apresentaram situações onde poderiam utilizar o conhecimento que foi obtido por meio do uso do JB. Os exemplos apresentados vão de encontro ao que foi apresentado por [Souza and Dourado 2015], que diz que a ABP, promove o processo de desenvolvimento de habilidades, competências e atitudes em todo processo de aprendizagem do tema, podendo aplicar os conceitos aprendidos em outros contextos da vida.

No tema Game Design, destaca os aspectos de implementação e interface do JB, bem como suas dificuldades e qualidades. Este tema foi dividido em três categorias: $(i)$ Compreensão, (ii) Dificuldades e (iii) Possibilidades do JB. A categoria Compreensão destaca a compreensão dos participantes em relação a interface do JB. Os participantes escreveram que a interface foi clara, explicativa e objetiva. Esses relatos estão de acordo com o trabalho de [Prieto et al. 2005], pois, segundo os autores, o apelo visual do jogo acaba chamando a atenção de jogadores, e até professores. A categoria Dificuldades destaca as dificuldades encontradas pelos participantes durante o uso do JB. Os principais problemas destacados foram: Problemas de segurança no download e mais interatividade na interface, como no tutorial. Por fim, a categoria Possibilidades do JB, apresenta relatos da experiência dos participantes com o JB. Os participantes destacaram que obtiveram uma experiência que provavelmente não teriam. Esse fato vai de encontro ao benefício de experiência de novas identidades promovido por jogos educacionais destacado por [Paiva and Tori 2017]. Neste, o jogador possui oportunidades de experiências de imersão em outros mundos e vivenciar diferentes identidades. No caso do JB, os participantes vivenciaram a vida de um biólogo que faz biorremediação de solos.

Para reforçar a tematização acima, destaca-se a pergunta feita aos participantes no final da apresentação. A pergunta representa uma situação real na qual pode-se chegar a uma solução por meio da biorremediação.

"Uma pessoa quer construir um shopping center, contudo o solo está contaminado, e os participantes foram contratados como consultores que dão o aval para permitir a construção com base na situação do solo. Após fazer todas as simulações, qual plano será traçado para resolver a situação desta pessoa?"

Os participantes responderam que deveria checar as condições do solo inicialmente e utilizar as bactérias que degradam o diesel e o biodiesel.

\section{Conclusão}

Com a evolução tecnológica, novas técnicas de aprendizado são desenvolvidas para fazer com que os alunos consigam aplicar os conhecimentos de uma forma mais agradável. A ABP utiliza uma abordagem onde os alunos enfrentam situações-problemas reais para melhorar a compreensão sobre um tema. Por outro lado, jogos educacionais são ferramentas de suma importância para exibir o conteúdo de forma amigável e interativa e, também, estimulando a competição e cooperação entre participantes.

Nesse contexto, este artigo apresentou a criação de um protótipo de jogo para o aprendizado de uma área importante da biologia que é a biorremediação. Cada fase 
do JB apresenta um desafio distinto para a construção do aprendizado de forma lúdica. Cada uma possui diferentes características de solo e de contaminantes, tornando o jogo dinâmico e requerendo que o jogador se adapte a diversas situações-problema. Ainda, o JB possui um ranking para estimular a competitividade entre jogadores e fortalecer o aprendizado.

Segundo os resultados da sequência didática, o JB apresentou resultados significativos. Os resultados mostraram que os participantes, mesmo com um período curto para jogar, conseguiram adquirir competências importantes importantes para o tema biorremediação. Ainda, foi possível observar que os participantes foram capazes de aplicar os conceitos em situações reais.

Durante a sequência didática, foi possível observar algumas limitações relacionadas à implementação do JB. Os participantes relataram problemas de segurança para a instalação do JB, devido ao fato de o sistema operacional reconhecer o arquivo executável como potencial vírus. Também foram relatados problemas com os gráficos do JB, o que impossibilitou o uso pelo participante 1. Relacionado ao design do JB, foi possível observar que durante a segunda e terceira etapa que os participantes não compreenderam completamente as situações-problemas apresentadas em cada fase. Bem como, não perceberam a influência das variáveis de ambiente (umidade, $\mathrm{pH}$, temperatura) na descontaminação e aumento da população de bactérias. Acredita-se que essa falta de percepção causou uma perda na evolução do conhecimento do tema biorremediação.

Apesar dos resultados da sequência didática indicarem um potencial do uso do JB como ferramenta de ensino de biorremediação, a sequência didática foi realizada com um número baixo de participantes. Entretanto, foi possível valiar a sequência didática para posterior aplicação com um número maior de participantes. Ressalta-se a dificuldade na realização da sequência didática, dado o cenário de pandemia, fazendo com que todas as etapas tivessem que ser realizadas de forma virtual. Apesar de facilitar o acesso, essa configuração diminui o controle sobre a realização da sequência didática.

Como trabalhos futuros, pretende-se resolver os problemas relatados pelos participantes. Outras funcionalidades a serem avaliadas são a inclusão de áudio para as ações do jogador, visando melhorar a ambientação no JB, inclusão de botões para configuração do JB (como ligar e desligar o som), bem como incluir as técnicas como fitorremediação e landfarming, para dinamizar o JB e possibilitar mais chances de vitórias aos jogadores.

Por fim, em relação ao game design, um trabalho futuro é criar uma história no jogo onde o jogador é um biólogo e, em cada fase, o jogo apresenta um jornal com uma notícia descrevendo o que aconteceu (por exemplo, um derramamento de petróleo). Essa notícia também mostrará o contaminante, bactérias e objetivo da fase com o intuito de facilitar o entendimento do jogador sobre a situação problemas da fase. Outro ponto é realizar o ajuste das variáveis de ambiente, encontrando um modo de equilibrar o impacto delas com a dificuldade na jogabilidade.

\section{Referências}

Andrade, J., Augusto, F., and Jardim, I. (2010). Biorremediação de solos contaminados por petróleo e seus derivados. Eclética Química, 35:17-43. 
Araújo, A. K. L., Araújo, D., Alves, S., and Lins, A. F. (2017). Jogos digitais na educação matemática. Encontro de Iniciação a Docência de UEPB. V ENID. Disponível em:< goo. gl/tQShhP>. Acesso em, 5 .

Atagana, H., Haynes, R., and Wallis, F. (2003). Optimization of soil physical and chemical conditions for the bioremediation of creosote-contaminated soil. Biodegradation, 14:297-307.

Carvalhal, M. L. C., Souza, R., and Carvalhal, M. L. C. (2002). Microligue: o jogo das associações. In Congresso Instituto Ciências Biomédicas, IV. Comissão de Cultura e Extensão Universitária do ICB/USP.

Carvalho, A. M. P. d. (2018). Fundamentos teóricos e metodológicos do ensino por investigação. Revista Brasileira de Pesquisa em Educação em Ciências, 18(3):765-794.

Fontoura, H. A. d. (2011). Tematização como Proposta de Análise de Dados na Pesquisa Qualitativa. Niterói: Intertexto.

Jacques, R. J. S., Bento, F. M., Antoniolli, Z. I., and de Oliveira Camargo, F. A. (2007). Biorremediação de solos contaminados com hidrocarbonetos aromáticos policíclicos. Ciência Rural, 37(4):1192-1201.

Mallmann, V., Aragão, L. W. R., Fernandes, S. S. L., Fernandes, T. C. L., Aragão, R. F. R., and da Silva, R. C. d. L. (2019). As vantagens da biorremediação na qualidade ambiental. Ensaios e Ciência C Biológicas Agrárias e da Saúde, 23(1):12-15.

Marques, F. P. (2019). Jogo eletrônico para apoio ao ensino de manejo agrícola. Diploma thesis, Centro Federal de Educação Tecnológica Celso Suckow da Fonseca (CEFET/RJ).

Paiva, C. A. and Tori, R. (2017). Jogos digitais no ensino: processos cognitivos, benefícios e desafios. XVI Simpósio Brasileiro de Jogos e Entretenimento Digital, pages $1-4$.

Prieto, L., Carmo, M., Trevisan, B., Danesi, M., and Falkembach, G. (2005). Uso das tecnologias digitais em atividades didáticas nas séries iniciais. RENOTE, 3.

Souza, S. and Dourado, L. (2015). Aprendizagem baseada em problemas (abp): Um mÉtodo de aprendizagem inovador para o ensino educativo. HOLOS, 5:182.

Spiegel, C. N., Alves, G. G., Cardona, T. S., Melim, L. M., Luz, M. R., Araújo-Jorge, T. C., and Henriques-Pons, A. (2008). Discovering the cell: An educational game about cell and molecular biology. Journal of Biological Education, 43(1):27-36.

Volkov, I., Banavar, J. R., Hubbell, S. P., and Maritan, A. (2003). Neutral theory and relative species abundance in ecology. Nature, 424(6952):1035-1037. 